Article

\title{
Ultrasonic Technology Applied against Mosquito Larvae
}

\author{
Kandasamy Kalimuthu ${ }^{1,+}{ }^{\dagger}$ Li-Chun Tseng ${ }^{1,+}{ }^{\dagger}$, Kadarkarai Murugan ${ }^{2}$, \\ Chellasamy Panneerselvam ${ }^{3}$, Al Thabiani Aziz ${ }^{3}$, Giovanni Benelli ${ }^{4}$ (D) \\ and Jiang-Shiou Hwang 1,5,*D \\ 1 Institute of Marine Biology, National Taiwan Ocean University, Keelung 20224, Taiwan; \\ biokalimuthu@gmail.com (K.K.); lichun@mail.bestredeye.org (L.-C.T.) \\ 2 Division of Entomology, Department of Zoology, School of Life Sciences, Bharathiar University, \\ Coimbatore 641 046, Tamil Nadu, India; kmvvkg@gmail.com \\ 3 Department of Biology, Faculty of Science, University of Tabuk, Tabuk 71491, Saudi Arabia; \\ cpselva@ymail.com (C.P.); aalthbyani@ut.edu.sa (A.T.A.) \\ 4 Department of Agriculture, Food and Environment, University of Pisa, via del Borghetto 80, 56124 Pisa, Italy; \\ giovanni.benelli@unipi.it \\ 5 Center of Excellence for the Oceans, National Taiwan Ocean University, Keelung 20224, Taiwan \\ * Correspondence: jshwang@mail.ntou.edu.tw; Tel.: +886-935289642 \\ + Both authors contributed equally to the present contribution.
}

Received: 8 April 2020; Accepted: 18 May 2020; Published: 20 May 2020

\begin{abstract}
The effective management of mosquito vectors is a timely challenge for medical and veterinary entomology. In this study, we evaluated the acoustic Larvasonic device to control young instars of the mosquito Aedes aegypti in diverse freshwater environments. Under laboratory conditions, we investigated the effect of exposure time and distance from the transducer on the mortality of larvae and pupae of Ae. aegypti. Furthermore, we evaluated the effectiveness of the ultrasound window of the electromagnetic spectrum under different field conditions. Results showed that first and second instar larvae were more sensitive to the frequency range of $18-30 \mathrm{kHz}$ of the Larvasonic device. Ultrasonic waves applied for $180 \mathrm{~s}$ at a frequency from 18 to $30 \mathrm{kHz}$ caused $100 \%$ larval mortality at a distance of $60 \mathrm{~cm}$ from the transducer. No mortality was observed in the non-target copepod Megacyclops formosanus. The exposure to the soundwaves produced by the acoustic larvicidal device over different distances effectively damaged Ae. aegypti through destruction of the larval dorsal tracheal trunk, thorax and abdomen. Overall, results indicated that the Larvasonic device tested can provide an alternative tool to reduce young instar populations of Ae. aegypti, without any effects on non-target aquatic invertebrates like copepods. It turned out to be a useful device for mosquito biocontrol. This technology has a relevant potential to fight the spread of mosquito-borne diseases.
\end{abstract}

Keywords: mosquito control; ultrasound; electromagnetic control; biological control; Aedes aegypti; Megacyclops formosanus; biosafety

\section{Introduction}

Mosquitoes (Diptera: Culicidae) transmit several of the most relevant life-threatening infectious diseases worldwide, including malaria, different types of encephalitis, lymphatic filariasis, West Nile virus, chikungunya, yellow fever, as well as Zika and dengue virus [1-5].

Recently, chikungunya and Zika virus emerged as two mosquito-borne viral diseases of major public health concern [6-8]. They are vectored by Aedes aegypti (L.) and Aedes albopictus (Skuse). Besides, a Flavivirus (Flaviviridae) mainly transmitted by the mosquito Ae. aegypti, is causing dengue fever, with significant human morbidity and mortality worldwide [9-11]. Annually, there are 
about 390 million humans infected with the dengue virus, with 96 million cases resulting in about 21,000 deaths. This worrying scenario urgently requires the development of effective measures for mosquito control $[12,13]$. The recent Zika virus outbreaks in many states of Brazil as well as on Pacific islands provide challenging examples [14-16]. In Brazil, Zika virus was ranked as one of the most serious public health issues, registering about 1.6 million cases in 2015 [17].

Mosquito vector control has the potential to reduce the impact of several mosquito-borne diseases $[18,19]$. Notably, since no effective vaccines against Aedes-vectored arboviruses are currently available, the control of vector populations at breeding sites remains crucial in urban and adjacent areas. Chemical insecticides are largely used for the management of mosquito populations, but they can be toxic to humans and non-target organisms, as well as for the environment [20]. They also led to the rapid development of insecticide resistance [21]. This situation demands new and safe mosquito control agents to reduce environmental and human health concerns [22-24]. In this study, we evaluated the efficacy of the Larvasonic apparatus based on ultrasound technology against Ae. aegypti larval instars developing in diverse aquatic breeding sites in Taiwan. Indeed, since Ae. aegypti widely exploits rather small water containers for oviposition and larval breeding, common in urban areas, it represents a suitable target for the Larvasonic device that was developed for acoustic transmission under water.

Ultrasound-based devices are used for other purposes, including microbiological control in aquaculture facilities, and for water treatment of ornamental water bodies and reservoirs [25]. Ultrasound was tested at strikingly different conditions on aquatic organisms, and effect studies are available from the earliest days of anti-mosquito ultrasound use [26]. It was observed that ultrasound can cause ruptures and bubbles that damage animal tissues. Tissue effects by cavitation are related to the duration, intensity, and frequency of acoustic waves [27]. The available ultrasound literature was already discussed by Colucci [28] in 2010, who applied ultrasound for algal control in a park pool of Austin, Texas, USA. Before that, ultrasound was used for wastewater treatment [29], as well as for anti-biofouling strategies in marine applications [30].

Concerning young instar management of mosquitoes, lower frequencies $(20-50 \mathrm{kHz})$ are generally more effective in killing mosquito larvae than higher frequencies $(>100 \mathrm{kHz})$, although the latter more efficiently produce free reactive radicals [31]. In another application, ultrasound-based technology was applied in the characterization of tissue and to evaluate animal carcass quality for human consumption. For instance, Morlein et al. [32] measured the intramuscular fat content using spectral analysis echo signals emitted by ultrasound treatment (at $\sim 3.5 \mathrm{MHz}$ ). In pigs, backfat thickness and the length of the musculus longissimus, as well as fat thickness of the back was measured using an ultrasound scanner (at $3 \mathrm{MHz}$ ), as a prediction of meat quality [33]. In poultry, breast muscle thickness, as determined by ultrasonography (at $7 \mathrm{MHz}$ ), was shown to provide a reliable measurement of meatiness [34]. In addition, body measurements and ultrasound images (at 3-7.5 MHz) were used to classify carcass traits of ducks [35], sheep [36], cattle [37], and catfish [38].

In the present study, we adopted a technology employing acoustic waves generated by a transducer to control developmental stages of the mosquito vector Ae. aegypti. Experiments were conducted both in laboratory conditions and field conditions. Firstly, we assessed whether the Larvasonic exposure times as well as the distance from the ultrasound source can differentially affect the mortality of young instars of Ae. aegypti. Furthermore, the mode of action of ultrasound-based technology was investigated, providing insights on the damages caused by the selected ultrasound frequencies on mosquitoes exposed to treatment when compared to individuals of the control. Finally, since data about the non-target impact of ultrasound-based technology against mosquito natural enemies are scarce, herein the effect of the Larvasonic device on the non-target invertebrate copepod Megacyclops formosanus (Harada, 1931) was investigated. This cyclopoid copepod is known as one of the most effective predators of interest for mosquito biological control. 


\section{Materials and Methods}

\subsection{Mosquito Rearing}

The Institute of Epidemiology, National Taiwan University, Taipei, Taiwan, provided eggs of Ae. aegypti. Following Suresh et al. [39], eggs were allowed to hatch in $18(\mathrm{~L}) \times 13(\mathrm{~W}) \times 4(\mathrm{D}) \mathrm{cm}$ enamel trays containing $500 \mathrm{~mL}$ of water. Mosquito larvae were subsequently reared at $27 \pm 2{ }^{\circ} \mathrm{C}$ and 75\%-85\% R.H. at a 14:10 (L:D) photoperiod. Larvae were fed brewer's yeast (Sigma Aldrich, Germany) and ground dog biscuits (Pedigree Company, MA, USA) at a 3:1 daily ratio.

\subsection{Copepod Culture}

Culture of the freshwater cyclopoid copepod M. formosanus was started by transferring 10 gravid females to a quartz glass aquarium filled with $3 \mathrm{~L}$ of culture medium consisting of ciliates, rotifers, and the alga Chlorella vulgaris Beijerinck 1890 in dechlorinated tap water. Copepods were then maintained at $27 \pm 3^{\circ} \mathrm{C}, \mathrm{pH}$ 7, and a photoperiod of 12:12 h (L:D) in an incubator at the Zooplankton and Coral Reef Laboratory, Institute of Marine Biology, National Taiwan Ocean University, Taiwan.

\subsection{Efficacy of Ultrasonic Treatment at Laboratory Conditions}

We adopted a technology employing acoustic waves generated by an ultrasound transducer, the Larvasonic apparatus (New Mountain Innovations Inc, Old Lyme, NY, USA) [5]. The transducer distributes acoustic energy uniformly in the horizontal plane and has a 360-degree volume of vertical coverage. In our study, the tested frequency range was $18-30 \mathrm{kHz}$. The transducer elements were made of piezoceramics with an output of $100 \mathrm{~W}$. Experiments were conducted in an open fish tank $87 \times 44 \times$ $44 \mathrm{~cm}^{3}$ filled with water up to a height of $20 \mathrm{~cm}, 100$ mosquito larvae (instars I, II, III, and IV, or pupae) were transferred to a net $\left(150 \mu \mathrm{m}\right.$ mesh size; $\left.2.3 \times 44 \times 44 \mathrm{~cm}^{3}\right)$ and placed inside a fish tank at 13 test points of distance $(0,5,10,15,20,25,30,35,40,45,50,55$, and $60 \mathrm{~cm})$ from the transducer immediately after starting the exposure to Larvasonic, lasting 30, 60, 90, 120, 150, $180 \mathrm{~s}$. Every experiment was replicated 5 times with new larvae or pupae. After each replicate, the number of dead mosquito larvae or pupae was noted. Non-target adults of the cyclopoid copepod M. formosanus were tested independently at the same distance and exposure time described above for Ae. aegypti larvae.

\subsection{Efficacy of Ultrasonic Treatment in the Field}

Field experiments were conducted in three selected areas (i.e., vegetable gardens, ditches, and waste tire stock sites) in Donggan, Nantou, and Keelung, Taiwan (Figure 1). Control samples of Ae. aegypti larvae were taken before treatment and after treatment by dipper sampling $(100 \mathrm{~mL})$, followed by larval counts. Several key factors that might impact experimental results were considered. These included the distance between the treatment device and the larvae that were collected in the field, and the size of the larval habitats. It was assured that the dipper samplings were able to collect larvae that sunk to the ground. Repeated collections were carried out to determine the differences in larval instar composition of the three collection sites. The selected environments were exposed to Larvasonic ultrasound pulses for $30 \mathrm{~s}$. Then, the collected samples were brought back to the laboratory to count live and dead mosquitoes daily for one week. Three replicates were conducted for each area from southern to northern Taiwan.

\subsection{Statistical Analysis}

For statistical analysis, descriptive statistical parameters such as mean and standard deviation values were calculated. Mortality (\%) data were then arcsine transformed to show that the data set had normality and homogeneity of variances. The effects of distance and period of exposure on each stage of mosquito larvae were analyzed using a two-way analysis of variance (ANOVA) followed by Tukey's honestly significant difference (HSD) test. Furthermore, the relation between mortality 
(\%), distance, and exposure time of all mosquito instars to the Larvasonic device were examined by regression analysis [40]. Distance and exposure time were used as predictors of mortality in a multiple regression analysis. SPSS software version 17.0 was used for the analysis.

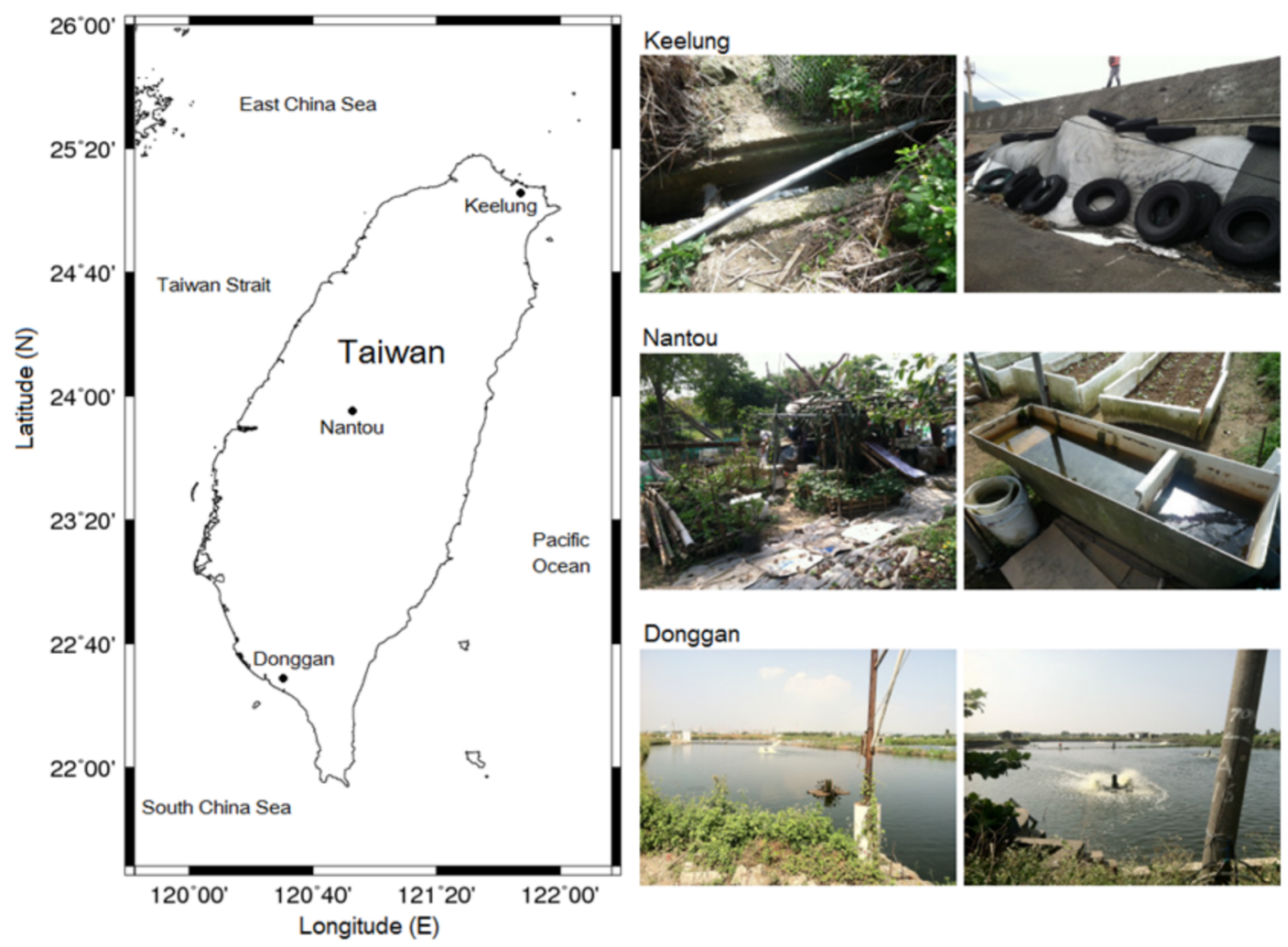

Figure 1. Map showing the field sample collection and study areas in Taiwan.

\section{Results}

\subsection{Laboratory Experiments}

In the laboratory, the effect of the ultrasonic wave spectrum at a frequency of 18 to $30 \mathrm{kHz}$ caused $100 \%$ mortality on Ae. aegypti larvae and pupae at $20 \mathrm{~cm}$ distance from the transducer after an exposure of $30 \mathrm{~s}$, and $100 \%$ mortality of instars I, II, and III at $35 \mathrm{~cm}$ after an exposure of $30 \mathrm{~s}$. It takes 180 s to kill all pupae at a distance of $60 \mathrm{~cm}$ (Figure 2). The mortality rates of Ae. aegypti were direct positively proportional to the exposure time $(p<0.05)$. All instars and pupae had $100 \%$ mortality at $20 \mathrm{~cm}$ after an exposure of $60 \mathrm{~s}(p<0.05)$. With increasing exposure time and fixed distance to the transducer, the percentage of Ae. aegypti larval mortality also increased $(p<0.05)$ (Figure 2). Two-way ANOVA results showed that the distance, exposure time, and their interaction significantly impacted each young instar stage of Ae. aegypti $(p<0.001$, Table 1). Among younger instars of this species, the fitted regression model revealed that mortality (\%) was significantly correlated to distance and exposure time $(p<0.001$, Table 2$)$. The coefficient values of distance were negative and showed a decreasing trend with extended space, whereas positive coefficient values of time indicated that accumulated effects increased the control efficiencies.

In our research, we used different life stages (I-IV larval instars and pupae) of the mosquito Ae. aegypti, as well as adults of the copepod M. formosanus (Figure 3). No mortality was found on the non-target copepod M. formosanus, as well as in pretreatments of mosquito larvae. The mortality of Ae. aegypti larvae caused by the Larvasonic device probably resulted from the sound energy transmitted into the water at a high frequency, leading to ruptures of the dorsal tracheal trunk in young mosquito instars, thus resulting in major tissue damage and death (Figure 4). 


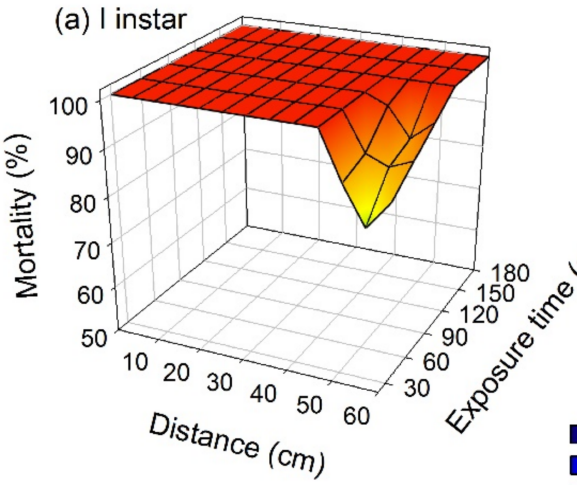

(c) III instar

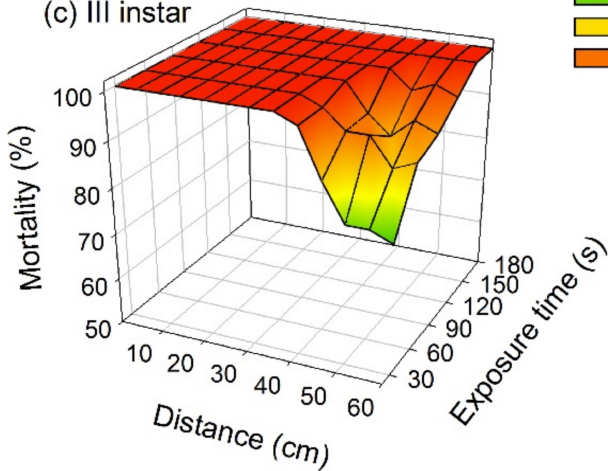

(e) Pupa

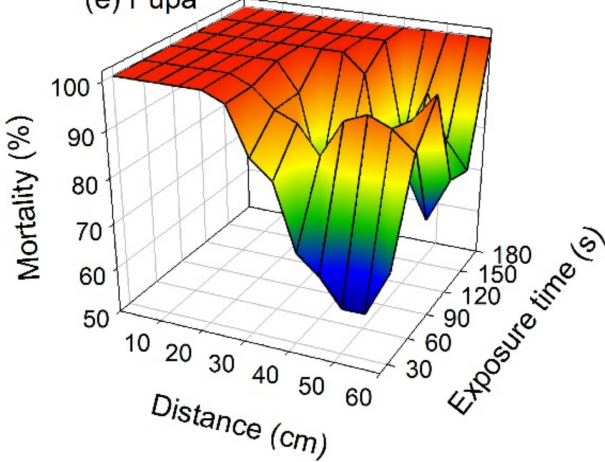

(b) II instar

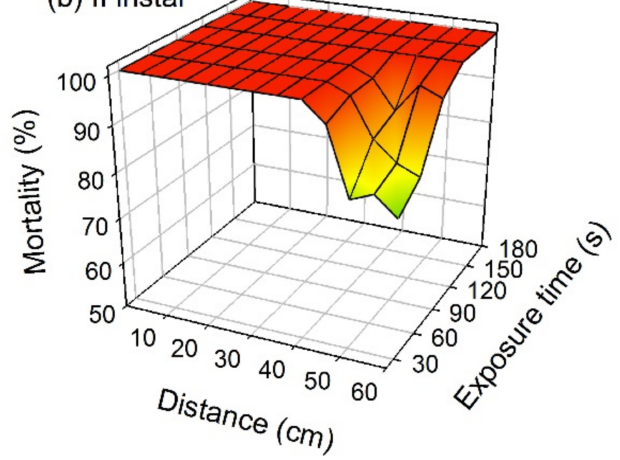

(d) IV instar

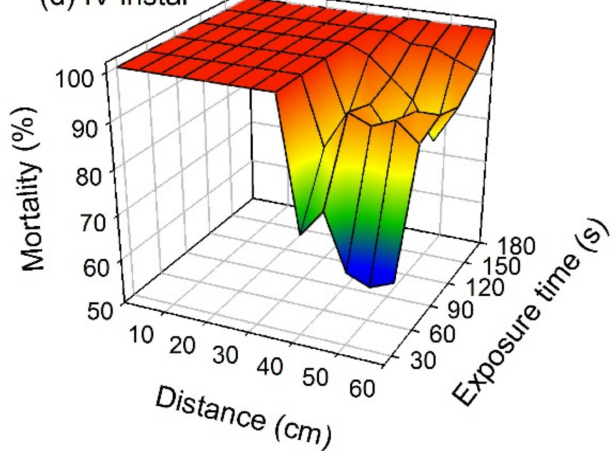

Figure 2. Mosquito mortality (\%) achieved by the Larvasonic treatment over different conditions on Aedes aegypti young instars.

Table 1. Results of two-way ANOVA testing the effect of distance and exposure time on Aedes aegypti young instars. The values of $d . f$. $=$ degree of freedom, significance level $p<0.05$.

\begin{tabular}{|c|c|c|c|c|c|}
\hline Source & Type III Sum of Squares & d.f. & Mean Square & $F$ & $p$-value \\
\hline \multicolumn{6}{|c|}{ I instar larva } \\
\hline Distance $(\mathrm{cm})$ & 0.99 & 12 & 0.08 & 18.24 & $<0.001$ \\
\hline Time (s) & 0.35 & 5 & 0.07 & 15.36 & $<0.001$ \\
\hline Distance $(\mathrm{cm}) \times$ Time $(\mathrm{s})$ & 1.23 & 60 & 0.02 & 4.54 & $<0.001$ \\
\hline Error & 1.41 & 312 & $<0.01$ & & \\
\hline \multicolumn{6}{|c|}{ II instar larva } \\
\hline Distance $(\mathrm{cm})$ & 1.66 & 12 & 0.14 & 47.86 & $<0.001$ \\
\hline Time (s) & 0.76 & 5 & 0.15 & 52.79 & $<0.001$ \\
\hline Distance $(\mathrm{cm}) \times$ Time $(\mathrm{s})$ & 2.27 & 60 & 0.04 & 13.09 & $<0.001$ \\
\hline Error & 0.90 & 312 & $<0.01$ & & \\
\hline \multicolumn{6}{|c|}{ III instar larva } \\
\hline Distance $(\mathrm{cm})$ & 2.29 & 12 & 0.19 & 37.74 & $<0.001$ \\
\hline Time (s) & 0.98 & 5 & 0.20 & 38.81 & $<0.001$ \\
\hline Distance $(\mathrm{cm}) \times$ Time $(\mathrm{s})$ & 2.16 & 60 & 0.04 & 7.15 & $<0.001$ \\
\hline Error & 1.57 & 312 & 0.01 & & \\
\hline
\end{tabular}


Table 1. Cont

\begin{tabular}{|c|c|c|c|c|c|}
\hline Source & Type III Sum of Squares & d.f. & Mean Square & $F$ & $p$-value \\
\hline \multicolumn{6}{|c|}{ IV instar larva } \\
\hline Distance $(\mathrm{cm})$ & 5.69 & 12 & 0.47 & 68.03 & $<0.001$ \\
\hline Time $(\mathrm{s})$ & 1.94 & 5 & 0.39 & 55.75 & $<0.001$ \\
\hline Distance $(\mathrm{cm}) \times$ Time $(\mathrm{s})$ & 3.67 & 60 & 0.06 & 8.78 & $<0.001$ \\
\hline Error & 2.17 & 312 & 0.01 & & \\
\hline \multicolumn{6}{|c|}{ Pupa } \\
\hline Distance $(\mathrm{cm})$ & 9.06 & 12 & 0.76 & 24.30 & $<0.001$ \\
\hline Time (s) & 3.21 & 5 & 0.64 & 20.64 & $<0.001$ \\
\hline Distance $(\mathrm{cm}) \times$ Time $(\mathrm{s})$ & 6.11 & 60 & 0.10 & 3.27 & $<0.001$ \\
\hline Error & 9.70 & 312 & 0.03 & & \\
\hline
\end{tabular}

Table 2. Fitted mixed contribution model for mortality $(\hat{y})$ of mosquito young instars (\%), evaluating the effect of the distance from the source of sound waves $(\mathrm{cm})$ and the exposure time (s). The numbers in parentheses are standard errors of the estimated coefficients shown above. Dist. = distance, ET $=$ exposure time.

\begin{tabular}{c}
\hline Treatment Group and Fitted Model \\
I instar larva \\
$\hat{y}=98.95-0.074$ (Dist.) $+0.021(\mathrm{ET})$ \\
$(0.53)(0.010)(0.004)$ \\
II instar larva \\
$\hat{y}=98.31-0.104$ (Dist.) $+0.032(\mathrm{ET})$ \\
$(0.59)(0.011)(0.004)$ \\
III instar larva \\
$\hat{y}=98.01-0.129$ (Dist.) $+0.037(\mathrm{ET})$ \\
$(0.62)(0.012)(0.004)$ \\
IV instar larva \\
$\hat{y}=96.46-0.235$ (Dist.) $+0.063(\mathrm{ET})$ \\
$(1.00)(0.019)(0.007)$ \\
Pupa \\
$\hat{y}=96.60-0.377$ (Dist.) $+0.070(\mathrm{ET})$ \\
$(2.08)(0.040)(0.015)$
\end{tabular}



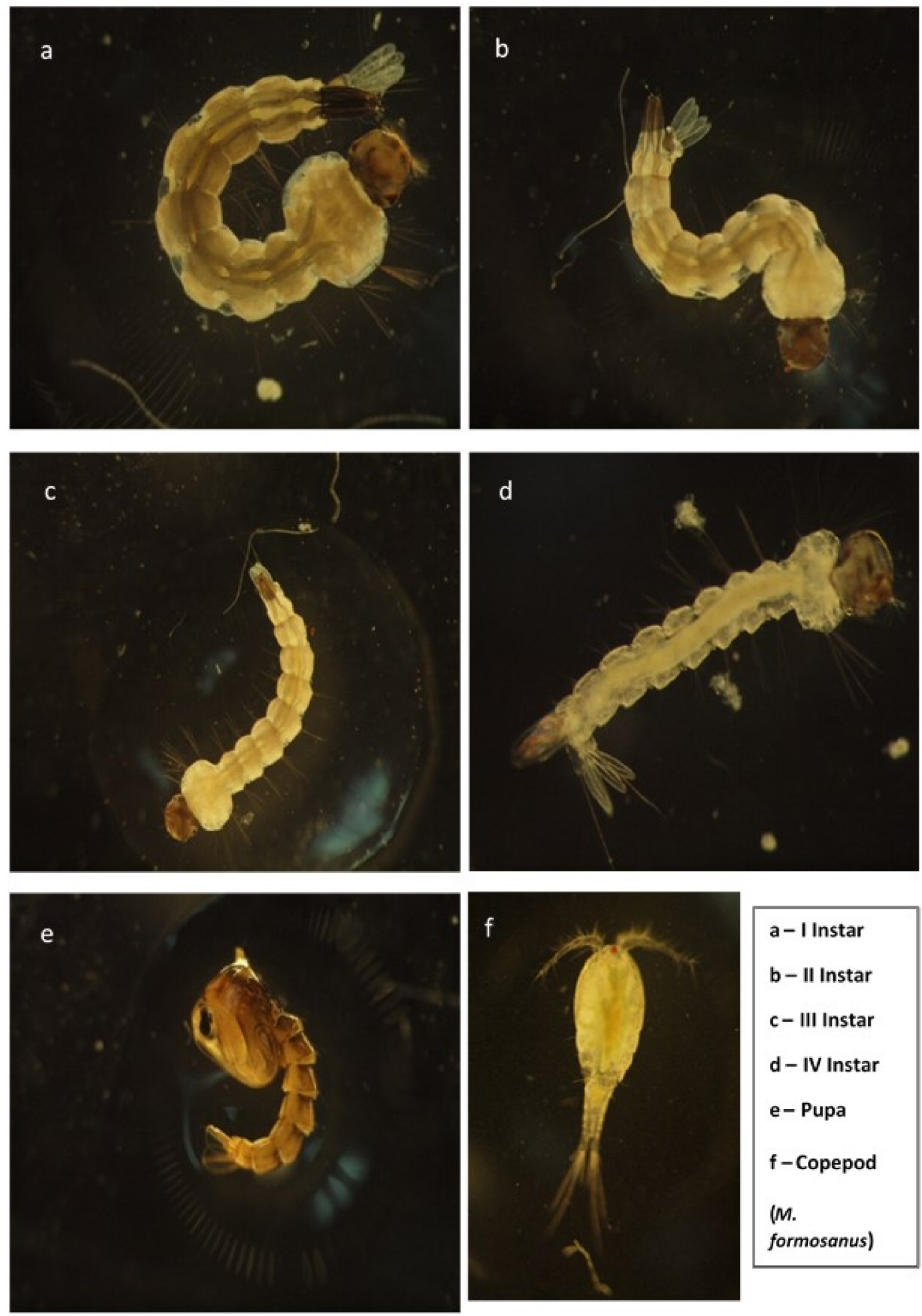

$$
\begin{aligned}
& \text { a - I Instar } \\
& \text { b - II Instar } \\
& \text { c - III Instar } \\
& \text { d - IV Instar } \\
& \text { e- Pupa } \\
& \text { f-Copepod } \\
& \text { (M. } \\
& \text { formosanus) }
\end{aligned}
$$

Figure 3. Young instars of Aedes aegypti before Larvasonic treatment: (a) I instar, (b) II instar II, (c) III instar, (d) IV instar, (e) pupae; and (f) non-target cyclopoid copepod Megacyclops formosanus. 

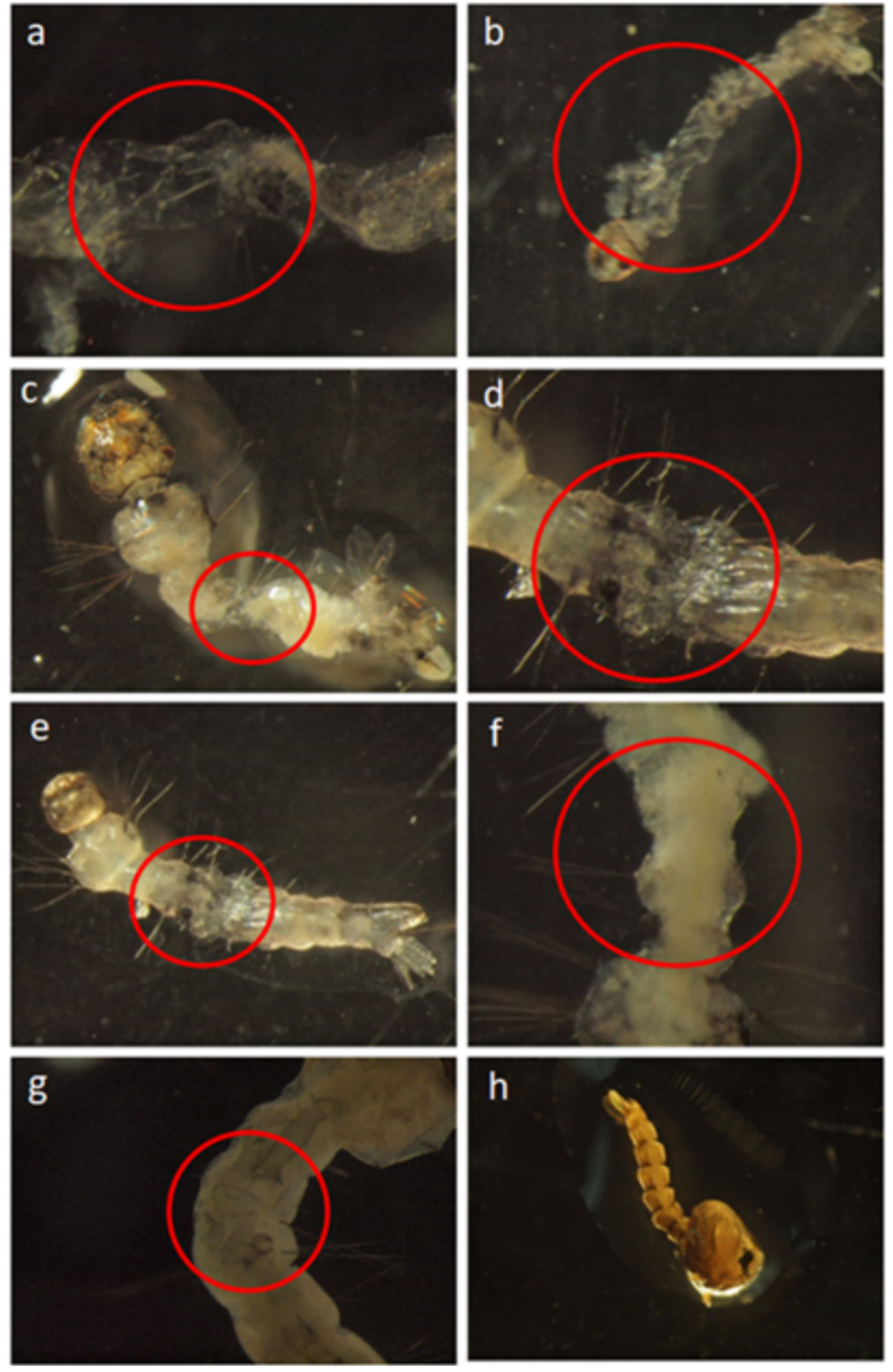

Figure 4. Post-treatment efficacy of Larvasonic under laboratory conditions against larvae (a-g) and pupae (h) of Aedes aegypti.

\subsection{Field Experiments}

In the field among the three selected study sites, the highest population of mosquito larvae was collected in a vegetable garden pond (42.31\%), followed by $38.46 \%$ in ditches, and $19.23 \%$ in waste tire sites of Donggan, Nantou, and Keelung (Figure 5a,b). In this research, we analyzed 26 field samples. Among them, the larval density was lower than 10 (individuals per liter) in 14 samples, followed by 20 to 40 (individuals per liter) in 3 samples, and 50 to 80 (individuals per liter) in only 1 sample (Figure $5 \mathrm{c}, \mathrm{d}$ ). The total sample analysis showed the presence of $21.36 \%$ of I instar larvae, $15.43 \%$ of II instar larvae, $28.62 \%$ of III instar larvae, $22.21 \%$ of IV instar larvae, and $12.36 \%$ of pupae. The reduction of the larval population after treatment was 95\%, which was highly significant $(p<0.001)$ (Figure 6a). Overall, data collected here showed that the ultrasonic waves at frequencies ranging from 18 to $30 \mathrm{kHz}$ were effective in controlling larvae and pupae of Ae. aegypti (Figure 6b). 

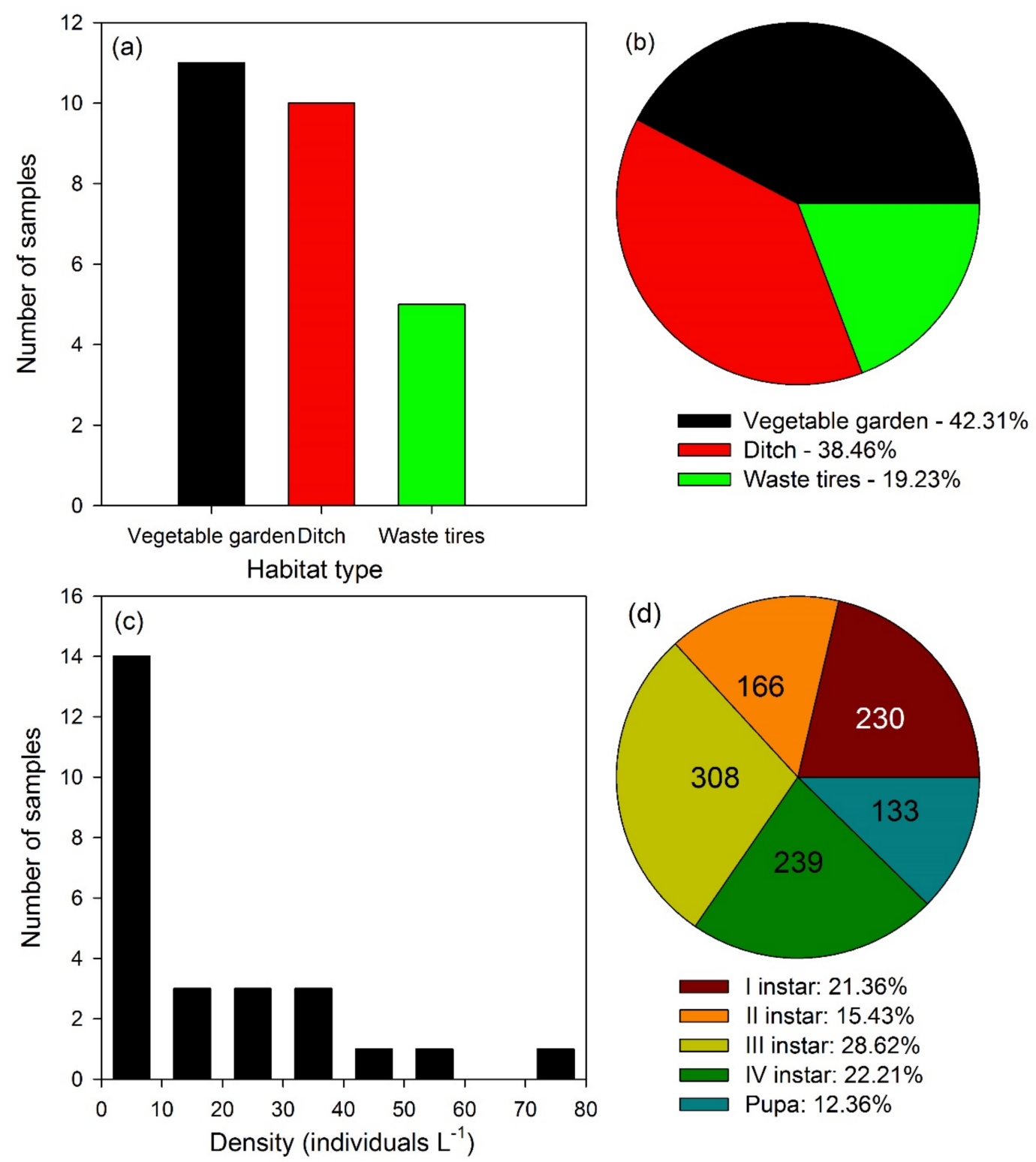

Figure 5. Number of mosquito larval samplings from different habitats surveyed in Taiwan (a,b). Aedes aegypti larval density over different samplings (c,d). 

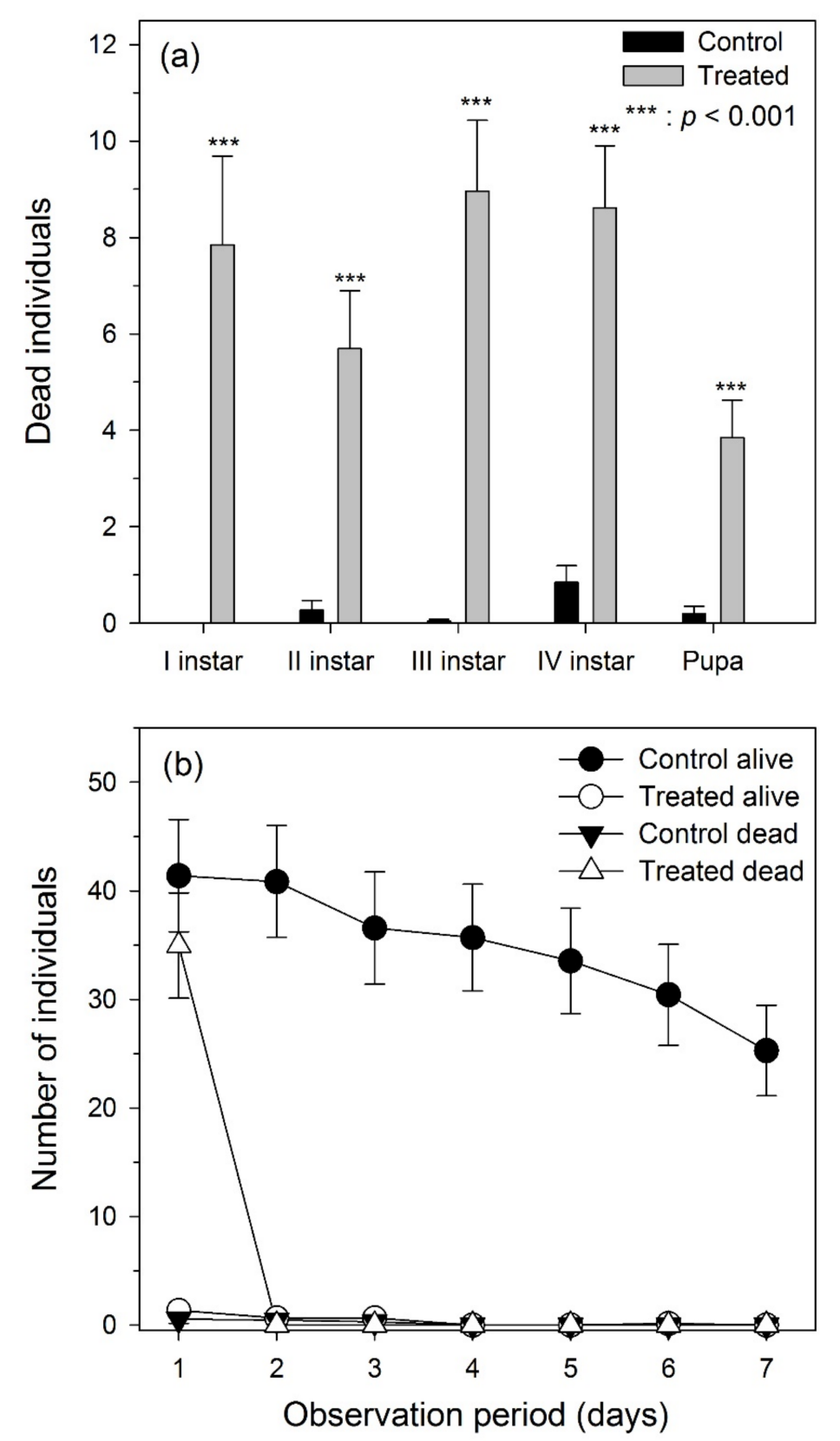

Figure 6. (a) Aedes aegypti larval mortality after of Larvasonic treatment. Asterisks indicate significant differences between control and treatment mortalities (ANOVA, Tukey's honestly significant difference (HSD) test, $p<0.05$ ). (b) Total mosquito larval mortality and survival after Larvasonic treatments. Data and statistical analysis consider the proportion of larvae/pupae killed or surviving and not absolute numbers that were killed.

\section{Discussion}

Ultrasound-based devices have been tested in a number of pest control attempts, developing several tools that provide sounds aiming to repel, deter, or kill unwanted animals such as arthropods, birds, rodents, and even larger mammals [41]. In particular, acoustic devices of various sizes and power levels were used successfully for insect pest management [42]. In our experiments, the morphological analysis of treated and killed Ae. aegypti larvae confirmed our hypothesis that the acoustic energy from the transducer broke the mosquito tracheal trunk in this species (Figure 4). It should also be noted that no matter the source and visibility by their avoidance, mosquitoes are able to detect ultrasound at a 
wavelength range of 38-44 kHz [43]. In agreement with our findings, Fredregill et al. [44] recently reported the efficacy of a Larvasonic Field Arm Mobile Wetlands Unit and SD-Mini in controlling Culex spp. mosquito populations, without any harmful effect on non-target organisms, including damselflies and dragonflies. Furthermore, Quraishi et al. [45] highlighted that ultrasonic waves at a frequency of $0.5 \mathrm{mc} / \mathrm{s}$ effectively inhibited the egg hatchability in Ae. aegypti. Also, Britch et al. [46] noticed that the Larvasonic SD-Mini acoustic larvicide achieved $90 \%$ mortality against Ae. aegypti. Besides, Foster and Lutes [47] reported that five ultrasonic waves at frequencies of $20-70 \mathrm{kHz}$ were effective in repelling mosquitoes.

From a mechanistic point of view at the cellular level, ultrasounds can cause membrane blubbing, shrinkage of cells, fragmentation of nuclei, chromatin condensation, and the fragmentation of apoptotic bodies [48-50]. Mehier-Humbert et al. [51] observed cuticle holes that were likely caused by ultrasound cavitation. Such porations can damage or kill mosquito larvae if the tissue holes are too large or if the tissues cannot reseal fast enough. In our research, we noticed that the tested sound waves resonate at the frequency of mosquito larva internal air volume, causing the larvae to burst. As a result, $98 \%$ of larvae and pupae were dead and the remaining $2 \%$ were alive with morphological deformation, ultimately resulting in their mortality within a short span of time. Concerning the impact of ultrasound on non-target organisms, we observed that ultrasonic waves employed at a frequency of 18 to $30 \mathrm{kHz}$ did not exhibit noticeable harmful effects on the copepod M. formosanus, which is a useful natural predator of mosquito young instars [52-54].

Vibrations caused by sound waves lead to the formation of gas vesicles that then resonate within and among the cells. Bubbles develop within cells, expand, and contract in a process of cavitational extension. Ultrasonic treatment leads to ruptures of the bubbles that are damaging the cells. Cavitational extension and with it the damaging effect on cells, is regulated by the frequency, intensity, and duration of sound waves [27]. These effects of ultrasonic waves do not only hold for mosquito young instar management but also for algal control. Other effects of ultrasonic waves include additional damage of cell membranes due to lipid peroxidation, and effects on the cell division cycle as evidenced from cyanobacteria $[55,56]$. Ma et al. [57] investigated the dynamics of microcystin release and degradation when Microcystis suspensions were treated with different ultrasound intensities and frequencies. Donskoy and Ludiyanskiy [58] showed that ultrasound can induce cavitation and mortality in veliger, juvenile, and adults of the invasive zebra mussel, applying 20-380 kHz.

Some aquatic insects are known to communicate by ultrasounds. Water boatmen (Hemiptera: Corixidae: Micronecta), for example, produce courtship songs which are partially in the ultrasonic range (about 5-22 kHz) [59]. Therefore, further research is required to understand the impact of ultrasound-based mosquito larvicidal treatments on the mating outcomes of aquatic Hemiptera. It should be noted that ultrasound may cause negative effects on some amphibians, since Pashovkin et al. [60] tested a variety of frequencies inducing striking mortality of Rana temporaria $\mathrm{L}$. embryos after 5 to $15 \mathrm{~min}$ at $0.88 \mathrm{MHz}$ and $0.2-0.7 \mathrm{~W} / \mathrm{cm}^{2}$. However, compared to the latter, our results are highly promising, since the Larvasonic device tested in this study at a frequency range of $18-36 \mathrm{kHz}$ did not lead to noticeable mortality on non-target cyclopoid crustaceans, which are also of interest for mosquito biocontrol [61].

Overall, in the present work we presented selected ultrasonic frequencies from 18 to $30 \mathrm{kHz}$ leading to high mortality of different young instars of Ae. aegypti. This supports the approach using acoustic waves for the management of mosquito larval populations. The present results showed that mosquito mortality is related to exposure time and distance from the transducer. The chemical and physical forces provided by ultrasonic cavitation lead to severe damage to cell membranes that subsequently kills developmental instars of the targeted mosquito species. Based on our results, ultrasound-based devices can be considered as a viable technology for mosquito control. Ecofriendly characteristics include that they are harmless to non-target invertebrates, such as the copepod M. formosanus. This particular copepod species could be used as an additional biocontrol agent, since we preliminarily also observed that its predation rates against mosquito larvae were not affected in our trials. 


\section{Conclusions and Challenges for Future Research}

This study provided three main results achieved through the employment of the Larvasonic device against Ae. aegypti young instars: (i) both the distance from the source of acoustic waves and the exposure time significantly affected mosquito larval mortality; (ii) the efficacy of the Larvasonic device was high even in the field over various Aedes breeding sites; and (iii) we did not detect negative impacts on the non-target copepod species $M$. formosanus, which is of interest for providing additional biological predatory control of mosquito larvae. The application of this method is particularly suitable for small urban and peri-urban water bodies where young instars of Ae. aegypti may develop at high densities. Therefore, the size of the experimental setup can be increased in future applications and research to assess the efficacy of this tool in large-scale real-world scenarios. Our laboratory and field studies suggest that an ultrasound-based technology has a good potential for future applications for mosquito larval control. Therefore, can be considered among integrated vector management tools to manage mosquito-borne diseases in an ecofriendly way.

As recommended by the World Health Organization in 2005, tests with new products and technologies should follow standard methodologies and should be carried out mainly with third and fourth instar mosquito larvae. In relation to the field experiment, another important factor affecting the efficacy of this tool is the volume of water at breeding sites, as already stressed in earlier researches [5]. Depending on the volume of water in the container, the effect can vary, thus decreasing larval mortality. Another factor is the timing of mortality after larval exposure in respective treatments. In addition, field tests should be carried out at larger scale.

The applied technology should be improved to minimize side effects on non-target species in aquatic ecosystems. In this framework, further research is still needed to assess the impact of the Larvasonic device on other aquatic non-target organisms. In addition, future in situ applications could include ultrasonic devices integrated in a remotely operating vehicle with a function similar to a vacuum cleaner. Furthermore, artificial intelligence could integrate signals of a laser sensor that would automatically detect and target mosquito larvae and pupae. This application would successfully manage mosquito populations, reducing environmental pollution and non-target effects of still widely used chemical insecticides.

Author Contributions: J.-S.H. conceived and designed the experiments. K.K. performed the laboratory experiments. K.K., L.-C.T., J.-S.H., and K.M. performed the field experiments. L.-C.T. and K.K. analyzed the data, prepared the figures, and wrote the original draft. J.-S.H. contributed reagents, materials, and analysis tools. K.K., L.-C.T., K.M., C.P., A.T.A., G.B. and J.-S.H. contributed to formal analysis, data curation and reviewed/edited the manuscript. All authors have read and agreed to the published version of the manuscript.

Funding: The authors are grateful for financial support from the Ministry of Science and Technology (MOST) of Taiwan through grant no. MOST 104-2611-M-019-004, MOST 105-2621-M-019-001, MOST 105-2918-I-019-001, MOST 106-2621-M-019-001, MOST 107-2621-M-019-001 and MOST 108-2621-M-019-003 to J.-S. Hwang, as well as the grant no. MOST 104-2811-M-019-005, MOST 105-2811-M-019-008, MOST 107-2811-M-019-004 and MOST 108-2811-M-019-504 to L.-C. Tseng. The funders had no role in study design, data collection and analysis, decision to publish, or preparation of the manuscript.

Acknowledgments: We appreciated the innovation and kind technical assistance of Herbert Nyberg (New Mountain Innovations, NY, USA), who developed the Larvasonic device. Finally, we thank Chih-Ming Lin for his assistance in manuscript submission.

Conflicts of Interest: The authors declare no conflict of interest.

\section{References}

1. Kilpatrick, A.M.; Randolph, S.E. Drivers, dynamics, and control of emerging vector-borne zoonotic diseases. Lancet 2012, 380, 1946-1955. [CrossRef]

2. Benelli, G.; Beier, J. Current vector control challenges in the fight against malaria. Acta Trop. 2017, 174, 91-96. [CrossRef]

3. Mayer, S.V.; Tesh, R.B.; Vasilakis, N. The emergence of arthropod-borne viral diseases: A global prospective on dengue, chikungunya, and Zika fevers. Acta Trop. 2017, 166, 155-163. [CrossRef] [PubMed] 
4. Benelli, G.; Lo Iacono, A.; Canale, A.; Mehlhorn, H. Mosquito vectors and the spread of cancer: An overlooked connection? Parasitol. Res. 2016, 115, 2131-2137. [CrossRef] [PubMed]

5. Nyberg, H.J.; Muto, K. Acoustic tracheal rupture provides insights into larval mosquito respiration. Sci. Rep. 2020, 10, 2378. [CrossRef]

6. Kindhauser, M.K.; Allen, T.; Frank, V.; Santhana, R.S.; Dye, C. Zika: The origin and spread of a mosquito-borne virus. Bull. World Health Org. 2016, 94, 675. [CrossRef]

7. World Health Organization. Guidelines for Laboratory and Field Testing of Mosquito Larvicides. 2005. Available online: https://apps.who.int/iris/handle/10665/69101 (accessed on 18 May 2020).

8. Lee, S.J.; Kim, J.H.; Lee, S.C. Effects of oil-film layer and surfactant of the siphonal respiration and survivorship in the fourth instar larvae of Aedes togoi mosquito in laboratory conditions. Sci. Rep. 2018, 8, 5694. [CrossRef]

9. Benelli, G. Research in mosquito control: Current challenges for a brighter future. Parasitol. Res. 2015, 114, 2801-2805. [CrossRef]

10. Murugan, K.; Aruna, P.; Panneerselvam, C.; Madhiyazhagan, P.; Paulpandi, M.; Subramaniam, J.; Rajaganesh, R.; Wei, H.; Alsalhi, M.S.; Devanesan, S.; et al. Fighting arboviral diseases: Low toxicity on mammalian cells, dengue growth inhibition (in vitro) and mosquitocidal activity of Centroceras clavulatum-synthesized silver nanoparticles. Parasitol. Res. 2016, 115, 651-662. [CrossRef]

11. Mendeiros-Sousa, A.R.; Fernandes, A.; Ceretti-Junior, W.; Wilke, A.B.B.; Marrelli, M.T. Mosquitoes in urban green spaces: Using an island biogeographic approach to identify drivers of species richness and composition. Sci. Rep. 2017, 7, 17826. [CrossRef]

12. Bhatt, S.; Gething, P.W.; Brady, O.J.; Messina, J.P.; Farlow, A.W.; Moyes, C.L.; Drake, J.M.; Brownstein, J.S.; Hoen, A.G.; Sankoh, O.; et al. The global distribution and burden of dengue. Nature 2013, 496, 504-507. [CrossRef] [PubMed]

13. Schwab, S.R.; Stone, C.M.; Fonseca, D.M.; Fefferman, N.H. The importance of being urgent: The impact of surveillance target and scale on mosquito-borne disease control. Epidemics 2017, 23, 55-63. [CrossRef] [PubMed]

14. Cardoso, C.W.; Paploski, I.A.; Kikuti, M.; Rodrigues, M.S.; Silva, M.M.; Campos, G.S.; Sardi, S.I.; Kitron, U.; Reis, M.G.; Ribeiro, G.S. Outbreak of exanthematous illness associated with Zika, chikungunya, and dengue viruses, Salvador, Brazil. Emerg. Infect. Dis. 2015, 21, 2274-2276. [CrossRef] [PubMed]

15. Benelli, G.; Mehlhorn, H. Declining malaria, rising dengue and Zika virus: Insights for mosquito vector control. Parasitol. Res. 2016, 115, 1747-1754. [CrossRef] [PubMed]

16. Boyer, S.; Calvez, E.; Chouin-Carneiro, T.; Diallo, D.; Failloux, A.B. An overview of mosquito vectors of zika virus. Microbes Infect. 2018, 20, 646-660. [CrossRef]

17. Brazilian Health Ministry. Dengue. Bol. Epidem. 2016, 47, 1-5.

18. Fernandes, J.N.; Moise, I.K.; Maranto, G.L.; Beier, J.C. Revamping mosquito-borne disease control to tackle future threats. Trends Parasitol. 2018, 34, 359-368. [CrossRef] [PubMed]

19. Lambert, B.; Sikulu-Lord, M.T.; Mayagaya, V.S.; Devine, G.; Dowell, F.; Churcher, T.S. Monitoring the age of mosquito populations using near-infrared spectroscopy. Sci. Rep. 2018, 8, 5274. [CrossRef]

20. Benelli, G. Plant-borne ovicides in the fight against mosquito vectors of medical and veterinary importance: A systematic review. Parasitol. Res. 2015, 114, 3201-3212. [CrossRef]

21. Naqqash, M.N.; Gökçe, A.; Bakhsh, A.; Salim, M. Insecticide resistance and its molecular basis in urban insect pests. Parasitol. Res. 2016, 115, 1363-1373. [CrossRef]

22. Benelli, G. Plant-mediated biosynthesis of nanoparticles as an emerging tool against mosquitoes of medical and veterinary importance: A review. Parasitol. Res. 2016, 115, 23-34. [CrossRef]

23. Pavela, R.; Benelli, G. Ethnobotanical knowledge on botanical repellents employed in the African region against mosquito vectors-A review. Exp. Parasitol. 2016, 167, 103-108. [CrossRef] [PubMed]

24. Hawkes, F.M.; Dabiré, R.K.; Sawadogo, S.P.; Torr, S.J.; Gibson, G. Exploiting Anopheles responses to thermal, odour and visual stimuli to improve surveillance and control of malaria. Sci. Rep. 2017, 7, 17283. [CrossRef] [PubMed]

25. Gina, L.; Elizabeth, H. Literature review of the effects of ultrasonic waves on cyanobacteria, other aquatic organisms, and water quality. Wisconsin DNR 2014, 195, 1-14.

26. Miller, D.L. The botanical effects of ultrasound: A review. Env. Exp. Bot. 1983, 23, 1-27. [CrossRef]

27. Rajasekhar, P.; Fan, L.; Nguyen, T.; Roddick, F.A. Impact of sonication at $20 \mathrm{kHz}$ on Microcystis aeruginosa, Anabaena circinalis, and Chlorella sp. Water Res. 2012, 46, 1473-1481. [CrossRef] 
28. Colucci, L.A. Ultrasonic algae control literature review. AWPD 2010, 7, 1-5.

29. Madge, B.A.; Jensen, J.N. Disinfection of wastewater using a 20-kHz ultrasound unit. Water Env. Res. 2002, 74, 159-169. [CrossRef]

30. Gómez Olmedilla, D. Preventing the Growth of Barnacles by Using Ultrasonic Sound. Master Thesis, Chalmers University of Technology, Göteborg, Sweden, 2012.

31. Mason, T.J. Large scale sonochemical processing: Aspiration and actuality. Ultrason. Sono. Chem. 2000, 7, 145-149. [CrossRef]

32. Morlein, D.; Rosner, F.; Brand, S.; Jenderka, K.V.; Wicke, M. Non-destructive estimation of the intramuscular fat content of the longissimus muscle of pigs by means of spectral analysis of ultrasound echo signals. Meat Sci. 2005, 69, 187-199. [CrossRef]

33. Cisneros, F.; Ellis, M.; Miller, K.D.; Novakofski, J.; Wilson, E.R.; McKeith, F.K. Comparison of transverse and longitudinal real-time ultrasound scans for prediction of lean cut yields and fat-free lean content in live pigs. J. Anim. Sci. 1996, 74, 2566-2576. [CrossRef]

34. Kleczek, K.; Wawro, K.; Wilkiewicz-Wawro, E.; Makowski, W.; Konstantynowicz, K. Relationships between breast muscle thickness measured by ultrasonography and meatiness and fatness in broiler chicken. Arch. Tierzucht. 2009, 52, 538-545. [CrossRef]

35. Farhat, A. Carcass characteristics of Peking ducks selected for greater breast muscle thickness using ultrasound scanning in response to dietary protein. Res. J. Agric. Biol. Sci. 2009, 5, 731-739.

36. Emenheiser, J.C.; Greiner, S.P.; Lewis, R.M.; Notter, D.R. Validation of live animal ultrasonic measurements of body composition in market lambs. J. Anim. Sci. 2010, 88, 2932-2939. [CrossRef] [PubMed]

37. Stelzleni, A.M.; Perkins, T.L.; Brown AHJr Pohlman, F.W.; Johnson, Z.B.; Sandelin, B.A. Genetic parameter estimates of yearling live animal ultrasonic measurements in Brangus cattle. J. Anim. Sci. 2002, 80, 3150-3153. [CrossRef] [PubMed]

38. Bosworth, B.G.; Holland, M.; Brazil, B.L. Evaluation of ultrasound imagery and body shape to predict carcass and fillet yield in farm-raised catfish. J. Anim. Sci. 2001, 79, 1483-1490. [CrossRef]

39. Suresh, U.; Murugan, K.; Panneerselvam, C.; Rajaganesh, R.; Roni, M.; Aziz, A.T.; Al-Aoh, H.A.N.; Trivedi, S.; Rehman, H.; Kumar, S.; et al. Suaeda maritima-based herbal coils and green nanoparticles as potential biopesticides against the dengue vector Aedes aegypti and the tobacco cutworm Spodoptera litura. Physiol. Mol. Plant. Path. 2018, 101, 225-235. [CrossRef]

40. Zar, J.H. Biostatistical Analysis, 4th ed.; Prentice Hall: Upper Saddle River, NJ, USA, 1999.

41. Frings, H. Pest control with sound waves; Ultrasonics as a possibility in the future of rodent and insect control. Pest. Control. 1948, 16, 9.

42. Mankin, R.W. Applications of acoustics in insect pest management. CAB Rev. 2012, 7, 1-7. [CrossRef]

43. Mohankumar, D. Ultrasound and Insects. 2010. Available online: http://www.electroschematics.com/3864/ ultrasound-and-insects/ (accessed on 18 May 2020).

44. Fredregill, C.L.; Motl, G.C.; Dennett, J.A.; Bueno, R.; Debboun, M. Efficacy of two larvasonic units against Culex larvae and effects on common aquatic non-target organisms in Harris County, Texas. J. Am. Mosq. Control. Assoc. 2015, 31, 366-370. [CrossRef]

45. Quraishi, S.M.; Osmani, M.H.; Ahmad, H.S. Effect of ultrasonic waves on the hatching of Aedes aegypti eggs at a frequency of $0.5 \mathrm{mc} . / \mathrm{s}$. J. Econ. Entomol. 1963, 56, 668-670. [CrossRef]

46. Britch, S.C.; Nyberg, H.; Aldridge, R.L.; Swan, T.; Linthicum, K. Acoustic control of mosquito larvae in artificial drinking water containers. J. Am. Mosq. Control. Assoc. 2016, 32, 341-344. [CrossRef] [PubMed]

47. Foster, W.A.; Lutes, K.L. Tests of ultrasonic emissions on mosquito attraction to hosts in a flight chamber. J. Am. Mosq. Control. Assoc. 1985, 1, 199-202. [PubMed]

48. Ashush, H.; Rozenszajn, L.A.; Blass, M.; Barda-Saad, M.; Azimov, D.; Radnay, J.; Zipori, D.; Rosenschein, U. Apoptosis induction of human myeloid leukemic cell by ultrasound exposure. Cancer Res. 2000, 60, 1014-1020. [PubMed]

49. Lagneaux, L.; de Meulenaer, E.C.; Delforge, A.; Dejeneffe, M.; Massy, M.; Moerman, C.; Hannecart, B.; Canivet, Y.; Lepeltier, M.F.; Bron, D. Ultrasonic low-energy treatment: A novel approach to induce apoptosis in human leukemic cells. Exp. Hematol. 2002, 30, 1293-1301. [CrossRef]

50. Tian, Z.M.; Wan, M.X.; Lu, M.Z.; Wang, X.D.; Wang, L. The alteration of protein profile of Walker 256 carinosarcoma cells during the apoptotic process induced by ultrasound. Ultrasound Med. Biol. 2005, 31, 121-128. [CrossRef] 
51. Mehier-Humbert, S.; Guy, R.H. Physical methods for gene transfer: Improving the kinetics of gene delivery into cells. Adv. Drug. Deliv. Rev. 2005, 57, 733-753. [CrossRef] [PubMed]

52. Dhanker, R.; Kumar, R.; Hwang, J.S. How effective are Mesocyclops aspericornis (Copepoda: Cyclopoida) in controlling mosquito immatures in the environment with an application of phytochemicals? Hydrobiologia 2013, 716, 147-162. [CrossRef]

53. Awasthi, A.K.; Wu, C.H.; Tsai, K.H.; King, C.-C.; Hwang, J.S. How does ambush predatory copepod Megacyclops formosanus (Harada 1931) capture mosquito larvae, Aedes aegypti? Zool. Stud. 2012, 51, 927-936.

54. Awasthi, A.K.; Molinero, J.C.; Wu, C.-H.; Tsai, K.-H.; King, C.-C.; Hwang, J.-S. Behavioral changes in mosquito larvae induced by copepod predation. Hydrobiologia 2015, 749, 113-123. [CrossRef]

55. Tang, J.W.; Wu, Q.Y.; Hao, H.W.; Chen, Y.; Wu, M. Effect of $1.7 \mathrm{MHz}$ ultrasound on a gas-vacuolate cyanobacterium and a gas-vacuole negative cyanobacterium. Coll. Surf. B Biointer. 2004, 36, 115-121. [CrossRef]

56. Zhang, G.; Zhang, P.; Liu, H.; Wang, B. Ultrasonic damages on cyanobacterial photosynthesis. Ultrason. Sonochem. 2006, 13, 501-505. [CrossRef] [PubMed]

57. Ma, B.; Chen, Y.; Hao, H.; Wu, M.; Wang, B.; Lv, H.; Zhang, G. Influence of ultrasonic field on microcystins produced by bloom-forming algae. Coll. Surf. B. 2005, 41, 197-201. [CrossRef] [PubMed]

58. Donskoy, D.M.; Ludiyanskiy, M.L. Low frequency sound as a control measure for zebra mussel fouling. In Proceedings of the Fifth International Zebra Mussel and Other Aquatic Nuisance Organisms Conference, Toronto, ON, Canada, 14-21 February 1995; pp. 103-112.

59. Sueur, J.; Mackie, D.; Windmill, J.F.C. So small, so loud: Extremely high sound pressure level from a pygmy aquatic insect (Corixidae, Micronectinae). PLoS ONE 2011, 6, e21089. [CrossRef] [PubMed]

60. Uteshev, V.K.; Pashovkin, T.N.; Sevirov, A.N.; Mel'nikova, E.V.; Sadikova, D.G.; Karnaukhov, V.N.; Gakhova, E.N. The survival of amphibian embryos after continuous ultrasonic treatment. Biofizika 2006, 51, 539-544. [CrossRef] [PubMed]

61. Awasthi, A.K.; Wu, C.H.; Hwang, J.S. Diving as an anti-predator behavior in mosquito pupae. Zool. Stud. 2012, 51, 1225-1234.

(C) 2020 by the authors. Licensee MDPI, Basel, Switzerland. This article is an open access article distributed under the terms and conditions of the Creative Commons Attribution (CC BY) license (http://creativecommons.org/licenses/by/4.0/). 